\title{
Investigation of pin-post monochromators for a wiggler beamline
}

\author{
Szczesny Krasnicki ${ }^{a}$, Jozef Maj ${ }^{a}$, Wilfried Schildkamp ${ }^{b}$, Thomas Tonnessen ${ }^{c}$ \\ ${ }^{a}$ Argonne National Laboratory, Advanced Photon Source \\ b The University of Chicago, \\ ${ }^{\mathrm{c}}$ Boeing North American, Albuquerque Operations
}

\begin{abstract}
Three water-cooled pin-post monochromators, to be used on a wiggler beamline at the Advanced Photon Source (APS), were built with the heat exchanger engineered to provide very high heat transfer. The geometry of the heat exchanger as well as calculated data on the heat transfer will be presented. Before using the monochromators on the beamline, they were checked by x-ray diffraction topography. Reflections (333) and (220) in Bragg case were utilized. In all crystals, similar patterns of strain in the diffracting silicon layers were revealed, which can be attributed to the geometry of the heat exchangers, the bonding technology, and the thickness of the top layer. Conclusions about construction of future pin-post monochromators have been drawn.
\end{abstract}

Keywords: synchrotron radiation, high-heat-load monochromators, heat transfer, topography, silicon bonding

\section{INTRODUCTION}

The third-generation $x$-ray synchrotron sources, such as the APS, produce beams of high power, power density and brilliance. Heat originating from absorption of the radiation in the first optical elements, e.g., monochromators, can induce thermo-mechanical strains in them or even destroy them. In the case of crystal monochromators, strains degrade their performance by decreasing the brilliance and/or coherence of the diffracted beam. Hence, first crystal optical elements require carefully designed cooling schemes.

Typically, directly cooled room-temperature single-crystal x-ray optics consists of some machined silicon pieces bonded to each other and attached to a metal manifold. In the top piece, a heat exchanger (HE) is machined under the diffracting surface. One possible design of the heat exchanger is the so-called pin-post structure ${ }^{1}$. For such structure a heat transfer coefficient in excess of $100 \mathrm{~W} / \mathrm{cm}^{2} \mathrm{~K}$ was achieved.

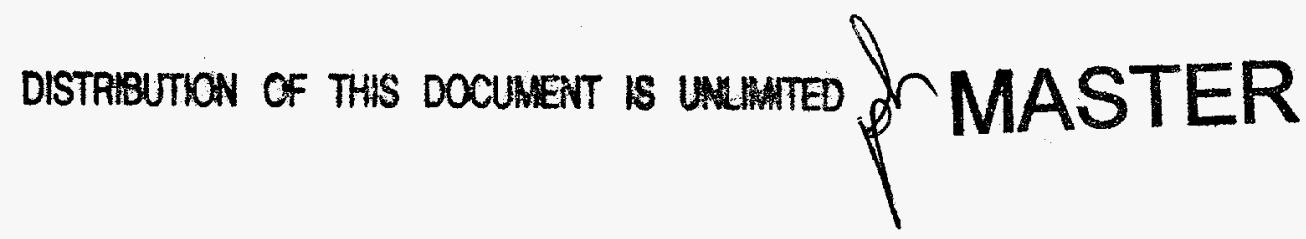

The submitted manuscript has been created by the University of Chicago as Operator of Argonne National Laboratory ("Argonne") under Contract No. W-31-109-ENG-38 with the U.S. Department of Energy. The U.S. Government retains for itself, and others acting on its behalf, a paid-up, nonexclusive, irrevocable worldwide license in said article to reproduce, prepare derivative works, distribute copies to the public, and perform publicly and display publicly, by or on behalf of the Government. 


\section{DISCLAIMER}

This report was prepared as an account of work sponsored by an agency of the United States Government Neither the United States Goverameat nor any agency thereof, nor any of their employees, makes any warranty, express or implied, or assumes any legal liability or responsibility for the accuracy, completeress, or usefulness of any information, apparatus, product, or process disclosed or represents that its use would not infringe privately owned righes. Refereace berein to any specirric commencial product, process, or service by trade name. trademarte inanufac. turer, or otherwise does aot necessarily constitute or imply its endorsement, recommeadation, of favoring by the United States Goverameat or any agency thereof. The views and opinions of authors expressed herein do not aecessarily sate or reflect those of the United States Government or any agency thereof. 


\section{DISCLAIMER}

Portions of this document may be illegible in electronic image products. Images are produced from the best available original document. 
Unfortunately, bonding of the cooling elements usually produces undesirable strains propagating to the diffracting surface. When the thickness of the crystal layer separating the diffracting surface and the heat exchanger is small, the residual strains in the diffracting layer can be significant. Taking into account the high cost of synchrotron radiation experiments, essentially all single crystals utilized for such experiments should be carefully tested before their use. A nondestructive and very sensitive to strain technique used to characterize almost perfect single crystals is high resolution x-ray topography ${ }^{2}$.

Recently, three water-cooled pin-post monochromators (physical surfaces parallel to (111) and (220) crystallographic planes) were built by Boeing North American company for The University of Chicago. The monochromators are to be used on a wiggler beamline at the Advanced Photon Source. Before implementing the monochromators on the beamline, they were tested by $\mathrm{x}$-ray diffraction topography at the Experimental Facilities Division of Argonne National Laboratory.

\section{DESIGN OF THE MONOCHROMATOR}

All three new monochromators were constructed in a similar way. A composite monochromator consists of four identically oriented silicon crystals and one nickel-iron base plate used to attach the composite to the relevant mechanical parts of the monochromator assembly. All silicon layers originated from the same ingot, and their primary thickness was $10 \mathrm{~mm}$ to provide sufficient strength and straightness during the subsequent machining and bonding procedures. The top layer contains the pin-post cell structure that was machined ultrasonically. Each cell is defined by square walls and contains nine pins. The design of cells was based on assumed water velocity of $10 \mathrm{~m} / \mathrm{sec}$. The water supply and return of each cell is located in diametrically opposite corners of the cell. The supply manifold of comb-like shape is milled into the second layer. Such shape was chosen so that large areas of the crystal would not be exposed to the water pressure. The return manifold has a similar shape and is milled into the third layer of silicon. The forth silicon layer is a simple base with two core-drilled supply and return holes. The registration of all four silicon layers is provided by two silicon dowel pins. Before assembling, all silicon parts were etched and lapped. The surfaces to be bonded were glassed, aligned by dowel pins, brought into contact, and bonded in a vacuum furnace by melting the glass. The top layer was then grounded and polished down to a total thickness of $1.2 \mathrm{~mm}$. The bonding procedure was described by $P$. Fernandez.

Pin-post cooling cells can reach exceptionally good heat transfer coefficients when water is used as the coolant. Calculation shows that, under reasonable assumptions for achievable flow rates, the heat transfer coefficients of the order of $50 \mathrm{~W} / \mathrm{cm}^{2} / \mathrm{K}$ can be achieved, far in excess of more typical transfer coefficient of $1.5 \mathrm{~W} / \mathrm{cm}^{2} / \mathrm{K}$ for macroscopic channels. The difficulty in achieving high heat transfer coefficients in the restricted volume of a small monochromator crystal is to provide enough cooling water to 
the small area of exposed crystal without deformation of the diffraction planes by pressurized manifold channels. We plan to employ water velocity of slightly higher than $10 \mathrm{~m} / \mathrm{sec}$ and to achieve an overall heat transfer coefficient from the face of the crystal to the water of about $60 \mathrm{~W} / \mathrm{cm}^{2} / \mathrm{K}$.

The crystals were designed to withstand the heating from a wiggler radiation spectrum with reasonable deformation. In order to economize on water consumption, the heat exchanger was divided into three regions. The pin-post cooling cells in all regions are identical, but the water supply is modified by different feeder diameters. The central $2 \mathrm{~cm} \times 1 \mathrm{~cm}$ part of the crystal, which is used normally for beam diffraction, is intensely cooled with water flow of 6.5 liters $/ \mathrm{min}$, whereas two marginal $1 \mathrm{~cm} \times 1 \mathrm{~cm}$ areas on both sides of the central region are cooled with flows of only $1.5 \mathrm{liters} / \mathrm{min}$. The marginal areas are to be cooled for safety reasons, i.e., they are needed for vertically missteered beams.

\section{TOPOGRAPHIC MEASUREMENTS}

Topographic tests of all three monochromator crystals were carried out in the X-ray Laboratory at the APS applying a Topo Test Unit ${ }^{4}$ and an $18 \mathrm{~kW}$ rotating anode as the $\mathrm{x}$-ray source. The measurements were performed in double-crystal ' $\mathrm{W}$ ' geometry using $8.04 \mathrm{keV}$ photons and silicon reflections (333) or (220). The diffraction plane was horizontal. The reflection of same Miller indexes was employed both for monochromator and sample crystals. The highly collimated, expanded, and monochromatic beams received after reflection from asymmetrically cut monochromators/collimators illuminated the whole front surfaces of the crystals tested.

The crystals were examined in two azimuthal positions, namely with the heat exchangers oriented vertically and horizontally. Examples of the rocking curves obtained at the optimized tilt positions are shown in Fig. 1. A summary of results of rocking curve measurements for all three composites are given in Table 1. For strain-free crystals, the FWHM of the rocking curve should be 2 arcsec for the (333) reflection and 5.25 arcsec for the (220) reflection.

Table 1.

$\begin{array}{lllc}\text { Crystal } & \text { Area illuminated } & \text { HE orientation } & \text { Average FWHM in arcsec } \\ \text { (111),\#1 } & \text { Total front surface } & \text { Horizontal } & 3.57 \\ & \text { Total front surface } & \text { Vertical } & 4.12 \\ (111), \# 2 & \text { Total front surface } & \text { Horizontal } & 3.37 \\ & \text { Central 0.68"x0.5" } & \text { Horizontal } & 4.42 \\ & \text { Central 0.34"x0.25" } & \text { Horizontal } & 3.78 \\ & \text { Central 0.17"x0.13" } & \text { Horizontal } & 2.97 \\ & \text { Total front surface } & \text { Vertical } & 3.78 \\ (220) & \text { Total front surface } & \text { Horizontal } & 5.89 \\ & \text { Central 0.64"x0.6" } & \text { Horizontal } & 6.12 \\ & \text { Total front surface } & \text { Vertical } & 6.37\end{array}$


Topographic images (topograms) of each crystal were taken for both azimuthal orientations at some positions on the corresponding rocking curve. Some topograms for the (111) composite No. 2 are reproduced in Figs. 2 and 3 . Due to the excellent collimation in the diffraction plane and a relaxed collimation in the vertical plane, our testing method is sensitive to different deformations of the reflecting crystallographic plane at two azimuthal positions of the sample.

The general features of topograms for all three samples are very similar. The topograms show irregularly distributed strains spread over all regions outside the heat exchangers with particularly strong features at the borders of the heat exchangers, and strain patterns with characteristic geometrical distribution in the regions of the heat exchangers.

\section{CONCLUSIONS}

Topographic tests of all three pin-post monochromators reveal the presence of strains/ deformations in the reflecting layers of crystals. The strains can be attributed to manufacturing procedures and/or bonding techniques and are observable due to the small thickness of the top layer. Residual strains in the parts of the crystals that do not contain the heat exchangers are of the order of 2.5 to 3 arcsec. Series of topograms taken along the rocking curves and values of FWHM given in Table 1 suggest that the heat exchangers cause minute overall bendings of the composite crystals in the planes normal to the front surface of the crystal. The stronger bending occurs in the plane normal to the longitudinal axis of the exchanger.

Of special interest are the strains in the central parts of the crystals above the heat exchangers. Generally speaking, the symmetry of observed strain is related to the pattern of supply and return feeder holes, not to the symmetry of the pin-post cell walls. In addition, on the topograms, it is possible to distinguish the central $2 \mathrm{~cm} \mathrm{x} 1 \mathrm{~cm}$ part of the heat exchanger and the outside regions.

The strain patterns observed suggests that either the surfaces of the manifold layers were not completely flat before bonding or that additional strain is produced by the lack of symmetry in bonding the glass coated surfaces. It is worth noting that the cell corners where feeder holes exist in the second layer are locally not bonded to the subsequent layer. Based on numbers shown in Table 1, the estimated deformation in the heat exchanger region is about 4 arcsec for the (111) crystal \#2 and 3.1 arcsec for the (220) monochromator.

Irrespective of the deformations observed, we believe that the investigated composite pin-post monochromators are acceptable for the anticipated use of these crystals in the $\mathrm{x}$-ray energy region below $17 \mathrm{keV}$. For applications at higher energies, we recommend a design with a thicker hot wall between the diffracting surface and the heat exchanger even 
though this would cause a poorer overall heat transfer. A $1.2 \mathrm{~mm}$ thickness of the hot wall seems to be a good compromise.

\section{ACKNOWLEDGMENTS}

This work was in part supported by NSF grant 9214163 (W. Schildkamp, PI) and in part by the U.S. DOE under BES, Contract No. W-31-109-ENG-38.

\section{REFERENCES}

1. T.W. Tonnessen, S.E. Fisher, "Design and Analysis of Cooled Optical Components for Synchrotron Beamlines", SPIE-Proceedings Vol. 1740, pp. 18-23 (1992)

2. D.K. Bowen, B.K. Tanner, "High Resolution X-ray Diffractometry and Topography", Taylor \& Francis, London, 1998

3. P.B. Fernandez, "Silicon Bonding Techniques on X-ray Optiocs", APS - LS Note 249

4. S. Krasnicki, "The APS Optics Topography Station", Rev.Sci.Instrum. 67 (9), 1996 
topo:scan1 (topo:scan1)

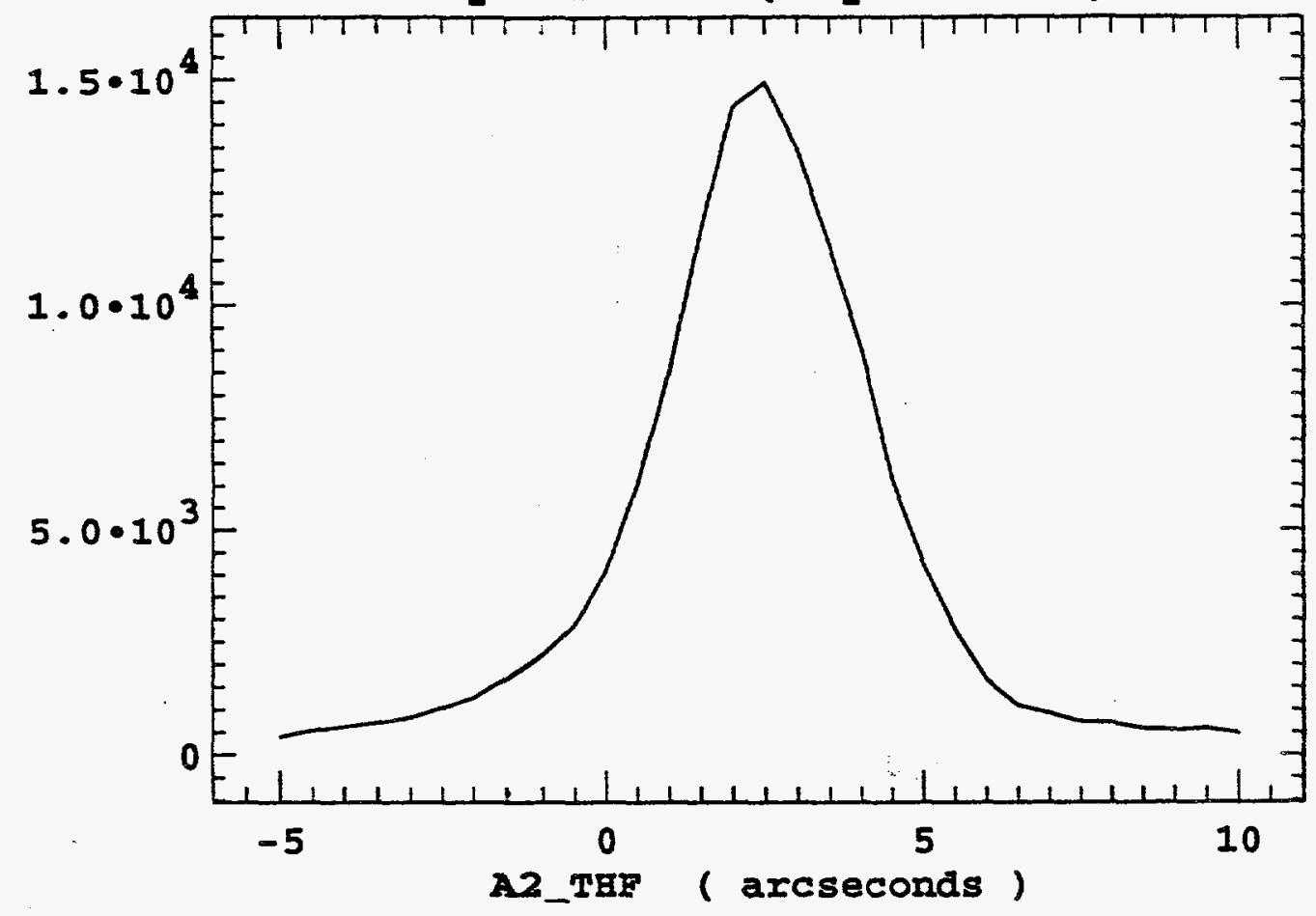

CB2

Peak Q2.5000036

Cntr e.2.4537975

FWEIM 3.3900504

Beak 14935.000

Fig. 1a Rocking curve for the (333) reflection from the composite (111) No.2 with the heat exchanger oriented horizontally.

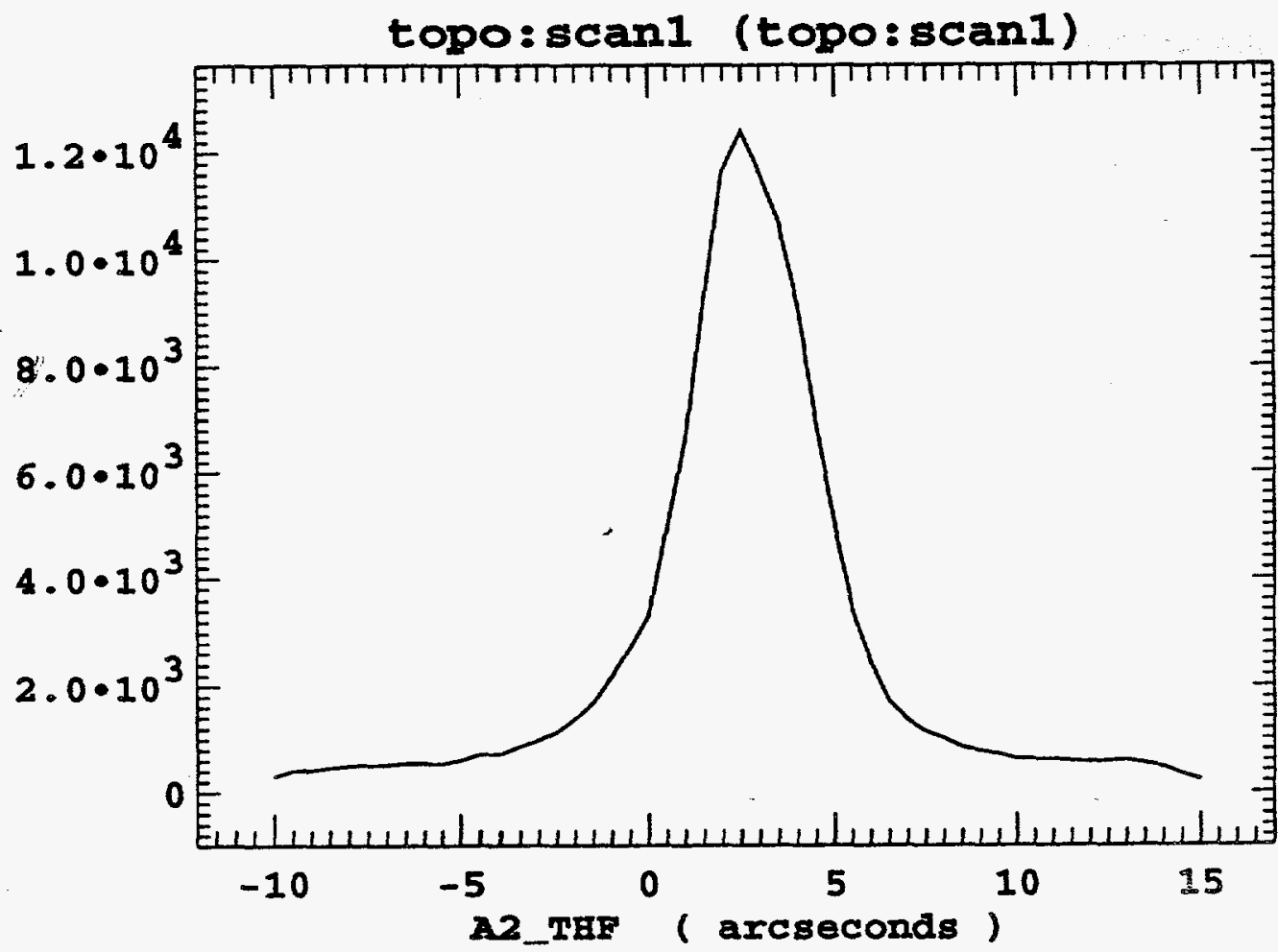

CH2

Peak e2.5000036

Cntr e2.6879345

FWTM 3.7602174

Peak 12404.000

Fig. 1b. Rocking curve for the (333) reflection from the composite (111) No.2 with the heat exchanger oriented vertically. 


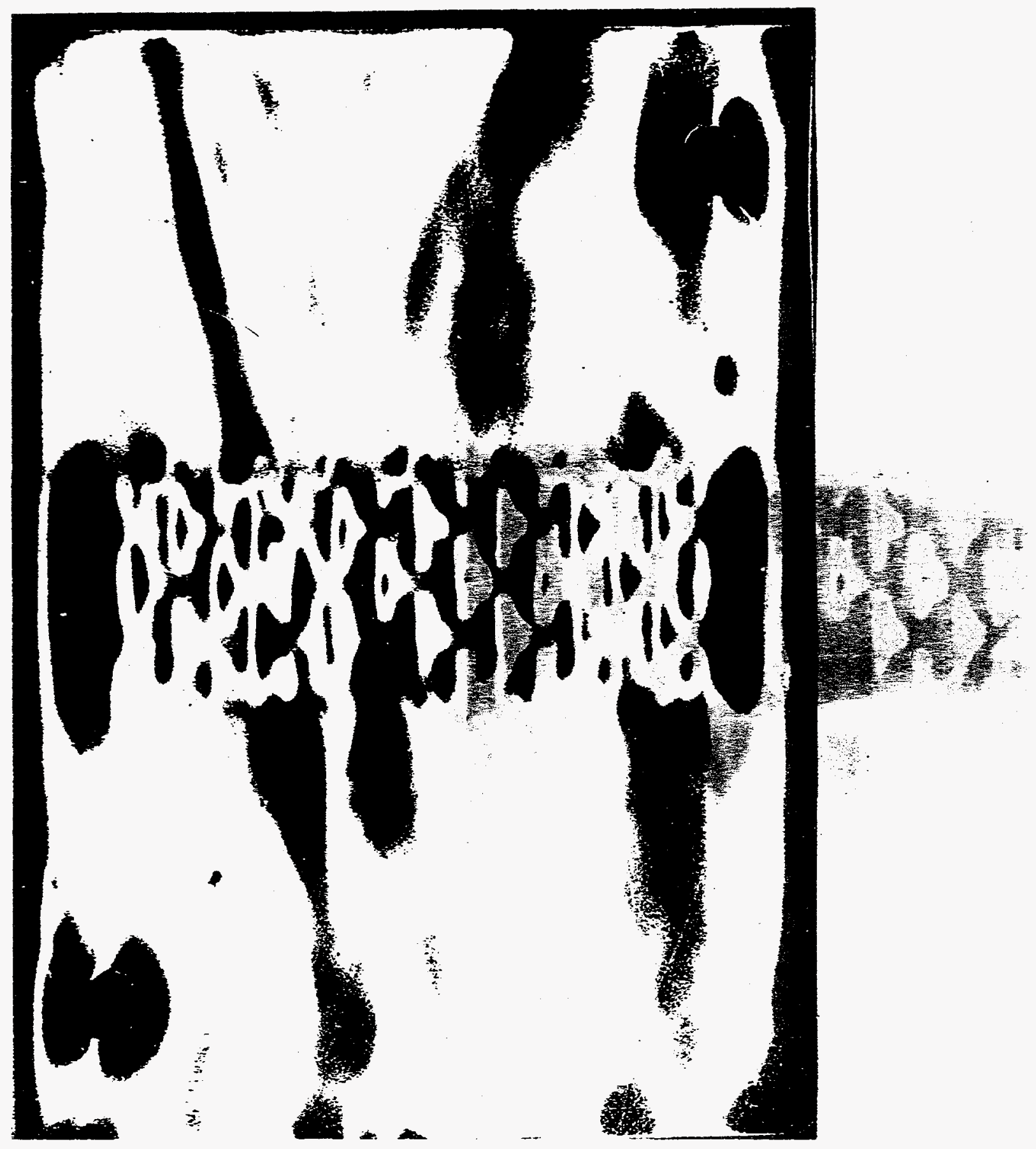

Fig.2. Topogram obtained for the composite (111) No2. at the top position of the rocking curve shown in Fig.la. 


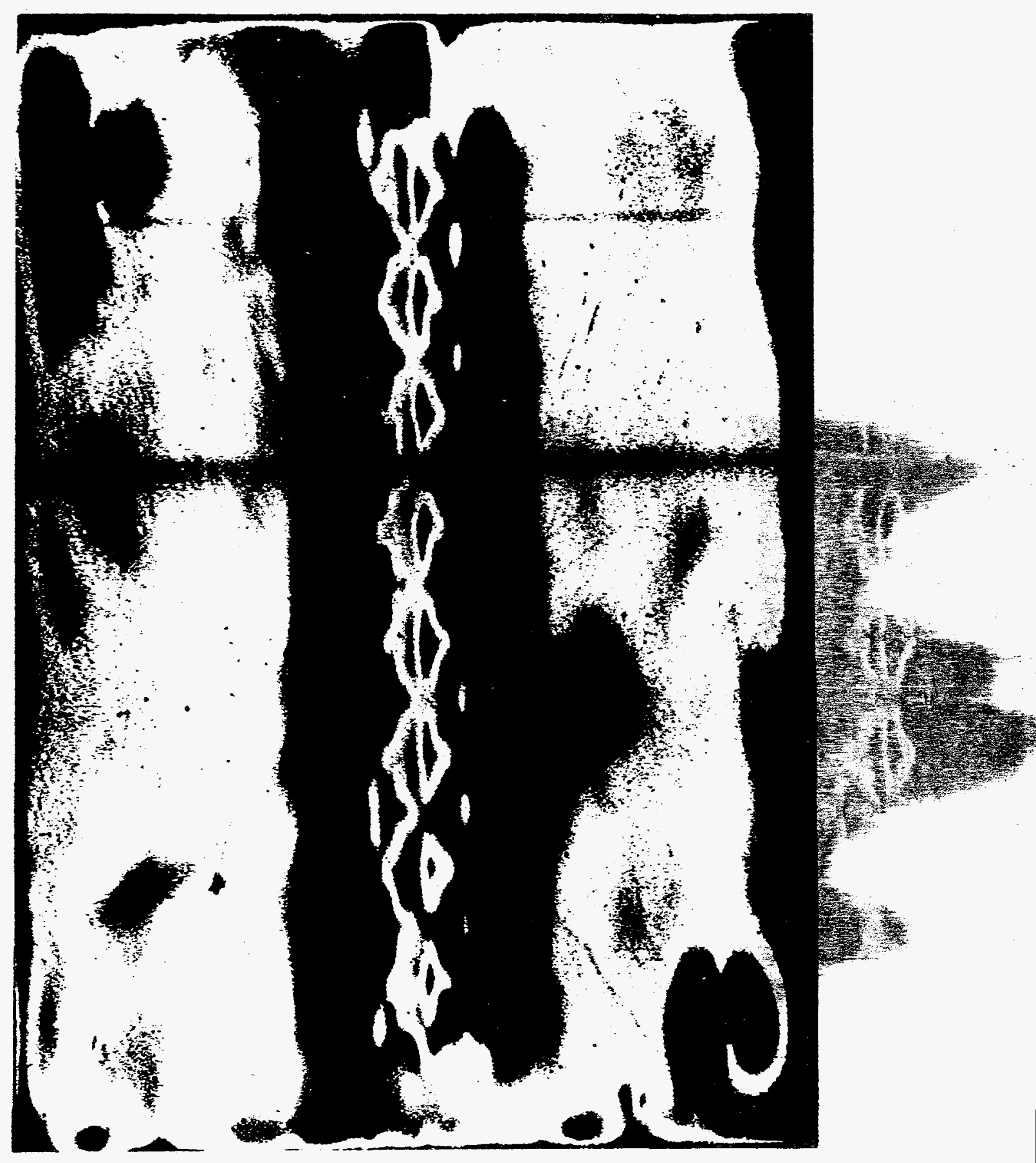

Fig.3. Topogram obtained for the composite (111) No2. at the top position of the rocking curve shown in Fig lb 